\title{
UM LETRAMENTO (NO) SINGULAR: A RETOMADA DA AGENDA REVOLUCIONÁRIA EM TEMPOS DE EDUCAÇÃO ULTRALIBERAL
}

\author{
CRITICAL LITERACY: THE RESUMPTION OF THE \\ REVOLUTIONARY AGENDA IN TIMES OF \\ ULTRALIBERAL EDUCATION
}

\section{Junia Claudia Santana de Mattos Zaidan}

\section{RESUMO}

Este trabalho discute o conceito de letramento crítico no contexto educacional brasileiro recente, que é parte de uma crise política mais ampla, em que emergem uma agenda ultraliberal, a despolitização da educação e a resultante escalada da violência em múltiplas formas, em todos os níveis da vida social. Recorrendo à historiografia do termo 'letramento' e a outras expressões que marcaram mudanças epistemológicas na área ao longo do tempo (novos letramentos, multiletramentos, etc.), argumentamos que é apenas através da retomada de uma agenda revolucionária nos estudos de letramento que o letramento crítico pode ser promovido neste estágio avançado do modo de produção capitalista.

Palavras-chave: letramento crítico; neoliberalismo e educação; violência e linguagem.

\section{ABSTRACT}

This paper discusses the concept of critical literacy in Brazil's recent educational context, which is part and parcel of a larger political crisis that includes the emergence of an ultraliberal agenda, the de-politicization of education and the resulting escalation of multiple forms of violence at all levels of social life. By drawing on the historiography of the term 'literacy' and other expressions that have marked epistemological changes in the field over time (new literacies, multiliteracies, etc.), we argue that it is only through the resumption of a revolutionary agenda in literacy studies that critical literacy can be fostered in the advanced stage of capitalist mode of production.

Keywords: critical literacy; neoliberal and education; language and violence.

Para Edna Castro de Oliveira

\section{CONSIDERAÇÕES INICIAIS}

Desde o início da Nova República - hoje declarada encerrada por muitos analistas - até o momento em que redijo este ensaio, com o Brasil experimentando

\footnotetext{
* Universidade Federal do Espírito Santo, UFES, Vitória, ES, Brasil. junia.mattos@hotmail.com Orcid: https://orcid.org/0000-0003-1857-3432
} 
um dos períodos mais dramáticos de sua história recente, nunca foi tão urgente uma postura afirmativa por parte de docentes, pesquisadoras e pesquisadores do campo da linguagem em relação às práticas sociais de leitura e escrita, que, aqui, chamamos de 'letramento crítico' (SOARES, 2002). A escalada da violência no país, o discurso de ódio, as perseguições a grupos socialmente vulneráveis, como negros, mulheres, LGBTTI, bem como o ataque aos movimentos sociais, à categoria docente e à liberdade de cátedra nas universidades públicas dão-se em um ambiente de ruptura institucional em vários níveis; um ambiente que tem se tornado cada vez mais policialesco e denuncista, convocando-nos a intensificar o trabalho teoricamente informado e empiricamente subsidiado de promoção das práticas de letramento crítico.

Por fomentarem o pensamento crítico, compreendido como a capacidade de dar sentido às diversas formas de materialização textual do discurso, identificar as assimetrias de poder e engajar-se no processo de transformação social, as práticas de letramento situam-se, necessariamente, no centro da luta pela refundação do Estado e constituem traço fundamental de qualquer retomada do desenvolvimento civilizacional, para a qual uma perspectiva educacional humanista é condição indispensável.

Dentre os muitos problemas a serem enfrentados na esfera educacional, hoje cada vez mais loteada pelas empresas privadas, e desfigurada em relação aos princípios estabelecidos na Lei de Diretrizes e Bases da Educação pelo ultraliberalismo emergente, levanto duas questões que se impõem aos estudos de letramento crítico. Primeiramente, destaco a crença na suposta redundância ou obsolescência das práticas de letramento, baseada no argumento de que os estudantes de língua materna ou estrangeira já as estariam experimentando na sociedade tecnologizada, independentemente da experiência escolar. Essa impressão generalizada, detectável entre professoras(es) e pesquisadoras(es), tem sido construída em um contexto em que a multimodalidade - sobretudo com a intensificação da digitalização dos processos de produção semiótica - tem alterado sensivelmente os modos de apropriação de recursos para as práticas de leitura e produção de texto. Essa visão, entretanto, desconsidera a disparidade de condições de acesso à educação entre as classes populares e as classes mais favorecidas, como discutiremos a seguir. Decorre desse problema um segundo, qual seja, a dessemantização do conceito de letramento, que, como argumentamos adiante, foi sofrendo certa captura pelo modo de produção capitalista a ponto de ser incorporado ao discurso acadêmico, sem contudo apresentar lastro na realidade social. Nessa realidade injusta - sobretudo socioeconomicamente - não basta pautar questões de gênero, sexualidade e étnico- 
raciais ligadas ao capacitismo ${ }^{1}$, ageísmo ${ }^{2}$, entre outras bandeiras identitárias, a fim de que o letramento produza as fissuras necessárias a uma real intervenção na sociedade. Em diálogo com a pedagogia freiriana, Menezes de Souza nos lembra que

(...) o processo de ler criticamente envolve aprender a escutar não apenas o texto e as palavras que o leitor estiver lendo mas também - e talvez mais crucialmente no mundo de conflitos e diferenças de hoje - aprender a escutar as próprias leituras de textos e palavras. Isso quer dizer que ao mesmo tempo em que se aprender a escutar, é preciso aprender a se ouvir escutando. Ler criticamente implica então desempenhar pelo menos dois atos simultâneos e inseparáveis: (1) perceber não apenas como o autor produziu determinados significados que têm origem em seu contexto e seu pertencimento sócio-histórico, mas ao mesmo tempo (2) perceber como, enquanto leitores, a nossa percep̧̧ão desses significados e de seu contexto sócio-histórico está inseparável de nosso próprio contexto sócio-histórico e dos significados que dele adquirimos. (MENEZES DE SOUZA, 2011, p. 131, ênfases do autor)

O imbricamento entre leituras do outro e de si e escuta do outro e de si é tomado como característica constitutiva da leitura do mundo; leitura essa indissociável dos dilemas, sofrimentos e violências vivenciados pela grande maioria dos povos em todos os lugares do mundo. Portanto, trazemos estas palavras iniciais para marcar um gesto metadiscursivo em relação aos problemas levantados, que, como indicamos, solicitam de nós ressignificações, reposicionamentos e reconceituações que reflitam nossas próprias experiências, percepções, incômodos, dificuldades, em face dos multilaterais ataques que a educação democrática tem hoje sofrido no Brasil. Ainda que neste momento a institucionalidade nos garanta tão pouco, este trabalho não propõe que abramos mão das instituições como um dos loci através dos quais encampamos a luta social, mas afirma que a batalha contra o obscurantismo nessa esfera se tornará possível através de micropolíticas de resistência e, principalmente, de luta.

Desejamos tecer esta conversa a partir de uma digressão, que, esperamos, fortalecerá os fios que vamos juntar adiante. Antes dela, contudo, reiteramos a imprescindibilidade de nosso engajamento em práticas de letramento, por natureza,

1. Capacitismo (em inglês, ableism) é o conceito para as diversas formas de discriminação em relação às pessoas com algum tipo de limitação física, sensorial ou intelectual, que produz, por exemplo, a naturalização de linguagem violenta, como "louco", "maluco", "doido", "imbecil", "idiota", "mongoloide". A fala, o pensamento e o sentimento em relação ao Outro (a quem geralmente se refere como "deficiente") e o Outro extraordinário, que seria, por consequência, "eficiente", constituem o discurso capacitista. (Cf. CAMPBELL, 2009)

2. Conceito forjado por Butler (1980, do inglês, ageism) para referir-se às atitudes discriminatórias em relação ao processo de envelhecimento, que se dinamizam socialmente de modo a produzir violência física e simbólica contra sujeitos idosos, aí incluídos, por exemplo, o impedimento ou o desfavorecimento de sua permanência do mercado de trabalho. 
inscritas na inter/transdisciplinaridade, em suas diversas formas (letramento visual, midiático, cultural, matemático, computacional, emocional etc.). $\mathrm{O}$ uso do plural e de outras expressões nesse campo (Novos letramentos, Multiletramentos, etc.) marca mudanças epistemológicas que receberão atenção na última seção deste texto.

\section{1. À GUISA DE ANALOGIA - CHARLOTTESVILLE E O DISCURSO DE ÓDIO COMO "LIBERDADE DE EXPRESSÃO"}

Em 2017, a marcha de Charlottesville, organizada pela direita ultranacionalista no estado norteamericano da Virgínia, teve desdobramentos que chocaram a opinião pública internacional. A morte de Heather Heyer, de 32 anos, e os ferimentos de dezenas de sujeitos, decorrentes do atropelamento em massa de autoria do supremacista branco James Alex Fields Junior, nos lembram que a chaga do racismo está longe de se fechar. A marcha "Unite the Right" composta por simpatizantes neonazistas a que o assassino de Heather Heyer compareceu antes de tentar assassinar manifestantes antirracistas é uma reiteração do racismo e da violência estruturais e estruturantes da/na sociedade estadunidense, que possuem, é claro, congêneres transnacionais. Por que essa história nos interessa para continuar a conversa sobre letramento? A pista está na resposta que a União Americana pelas Liberdades Civis (UALC), sempre dedicada a defender a liberdade de expressão, deu ao incidente: processando a cidade de Charlottesville em nome do organizador da referida marcha de ultradireita, ou seja, defendendo o suposto direito de supremacistas brancos irem às ruas proferir expressões injuriosas contra pessoas de cor $^{3}$. Duramente criticada por defensores dos direitos humanos, grupos progressistas e até mesmo parte da mídia mainstream, a UALC se vale da primeira emenda da Constituição dos Estados Unidos sobre a liberdade de expressão, alegando que defende o direito de os líderes supremacistas protestarem.

O gesto da UALC produz a sensação de que ela ignora que grupos supremacistas e protestantes antirracistas não estão lutando de igual para igual, sob as mesmas condições, sobretudo no contexto de um governo em que resta inequívoco o pendor para o racismo e a xenofobia ${ }^{4}$, para mencionar apenas alguns

3. Nos Estados Unidos, a expressão 'pessoas de cor' ("person of color" ou, seu plural, "people of color") inclui negros, latinos, asiáticos e outros sujeitos não identificados como brancos.

4. O pronunciamento de Donald Trump, Presidente dos Estados Unidos, sobre o crime, em que menciona a "culpa em ambos os lados" (SHEAR \& HABERMAN, 2017, ênfase nossa) e sua postagem na rede social Twitter afirmando que "No matter our color, creed, religion or political party, we are all American first", dão a ver sofisma semelhante àquele em que se baseou a UALC: que a 
problemas. Assim, em nome da liberdade de expressão, prescinde-se da violência física e simbólica sofrida diariamente pelas comunidades marginalizadas e, ainda que não invisíveis, invisibilizadas tanto pelo poder público, quanto pela mídia de massa. Quando há disparidade no acesso à esfera pública em que apenas a voz de um determinado grupo é projetada ${ }^{5}$, defender a igualdade pode significar defender a violência, simplesmente porque não há, de partida, igualdade de condições. Estas incluem, por exemplo, a garantia da livre expressão, a visibilidade, o tratamento equânime por parte da polícia, igualdade de oportunidades para acesso aos bens materiais e culturais, de condições socioeconômicas, dentre outras de que sujeitos negros sofrem privação.

A analogia que proponho entre o incidente narrado e nossa questão relativa à necessidade de desenvolver práticas de letramento(s) no ensino de línguas materna e estrangeira está na pressuposição comum às duas situações em relação à existência de um contexto em que certos processos já teriam se consolidado: no caso de Charlottesville, a igualdade de condições entre as pessoas de cor e a população branca, que implicaria a aderência do conceito de liberdade democrática; no caso de nosso contexto escolar, parece presumir-se a apropriação das práticas multimodais de leitura e escrita em um mundo digital. Decorre de situações distintas, daí a analogia, um resultado comum, qual seja, a privação de acesso aos bens materiais e culturais, tanto para a população de cor, quanto para os sujeitos do sistema educacional brasileiro. Valida-se a desigualdade substantiva (entre um grupo social e outro; entre uma realidade escolar e outra) em nome de uma igualdade formal.

Estabelecida a analogia, podemos examinar cada caso a partir de uma distinção conceitual oportuna, muito evocada em discussões no campo da Filosofia e do Direito, entre o ser e o dever ser; indo de encontro à falácia naturalista (MOORE, 1903, também relacionável a HUME, 1888), segundo a qual, se as coisas são de um jeito (premissa factual) é porque devem ser como são (premissa de caráter prescritivo). Dito de outro modo, derivaríamos o deve ser do é, como nos lembra Rajagopalan

sociedade ideal - justa e equânime - está pronta, já foi construída e que os sujeitos desfrutam de igualdade de condições, atuando com proporcional e justa participação e projeção nos processos sociais. Trata-se de uma base discursivamente violenta, pois apaga a disparidade socioeconômica, racial, de gênero, etc.; silencia a voz subalterna, produz, banaliza e perpetua a violência (Cf., por exemplo, DELGADO \& STEFANCIC, 2001; WILLIAMS, 1989, 1991; 1997; PRICE, 2004, que desenvolvem trabalho ligado à Teoria Racial Crítica no contexto estadunidense).

5.Cf. Gomes (2008), para uma discussão sobre o conceito de esfera pública e Habermas (2008), sobre a relação entre a esfera pública e a comunicação social. 
$(1996)^{6}$, reduzindo nossa percepção e ação no mundo e naturalizando o status quo (o que é). Falaciosa, pois, nessa premissa, é a negação da possibilidade de, reconhecendo o estado atual de uma situação, rejeitar que (a inexorabilidade de) sua perenidade seja dada.

Retomando o incidente de Charlottesville, se o que bá, com efeito, é disparidade entre grupos sociais em relação ao acesso à livre expressão, como poderemos considerar alcançada a livre expressão que deve haver? Dizer que há liberdade de expressão seria ratificar, falaciosamente, a suposta existência do acesso à voz pública, inviabilizando discursivamente a luta por transformação nesse campo. Vamos ao nosso letramento, se o que há, de fato, é disparidade entre escolas, setores público e privado, escolas públicas na periferia e escolas públicas em bairro privilegiados, comunidades, bairros e cidades no território brasileiro, ao defender que as práticas de letramento foram apropriadas no cotidiano escolar, não estaríamos produzindo, na verdade, a naturalização da privação: as coisas são do jeito que devem ser? Elaboremos mais, cotejando as duas situações. Como prescindir da violência física e simbólica a que os negros foram e são historicamente sujeitados (reconhecimento que se situa no campo do que é) para defender a liberdade (o que deve haver?) de supremacistas brancos destilarem livremente seu discurso de ódio em nome da liberdade de expressão? Analogamente, ainda que pareça radical comparar as duas situações, presumir que a escola incorporou as práticas sociais tecnologizadas (multimodais) de leitura e escrita, e que seus sujeitos são autônomos para escolher os recursos semióticos que desejarem não significaria correr o risco de desconsiderar a violência simbólica que lhes nega a apropriação dessas práticas devido à precariedade crescente do sistema educacional brasileiro, sobretudo, mas não somente, desde a aprovação da Proposta de Emenda Constitucional 55 - de congelamento dos recursos para a educação e saúde por 20 anos (a PEC do teto de gastos)? Nessa pergunta, apontamos para aspectos ligados à estrutura física, aos recursos materiais básicos, aos recursos humanos ${ }^{7}$, embora não precisemos a eles

6. Rajagopalan (1996) argumenta que a distinção entre estas categorias poderá induzir à ideia equivocada de que é possível separar uma afirmação de um juízo de valor. Nesta crítica à pragmática de John Searle, Rajagopalan argumenta que afirmações factuais não têm caráter ontológico, mas assertivos, sendo, assim, sujeitas à regulação exterior, ou seja, são tão ideológicas quanto as proposições avaliativas.

7. Enquanto redigíamos este capítulo, seguia o processo de precarização da educação pública capixaba através da oficialização de acordo de cooperação entre o governo e o setor privado, tornando possível a contratação de pessoal sem curso de licenciatura para atuar na sala de aula e exigindose apenas um treinamento de cinco semanas. A Portaria conjunta SEDU/ SEGER N ${ }^{\circ} 002-\mathrm{R}$, de 11 de setembro, que tornou público o Acordo de Cooperação $n^{\circ}$ 001/2017, firmado em 15 de agosto deste ano "com organização do setor privado, sem fins lucrativos na área da educação, e sem custos para o Erário", foi publicada no Diário Oficial do Estado do Espírito Santo (Executivo, fls. 21-22), em 13 de setembro de 2017. (disponível em: http://ioes.dio.es.gov.br/portal/visualizacoes/ pdf/3875/\#/p:29/e:3875? find ="343154") 
nos restringir para argumentar em favor da proposição afirmativa do letramento, ainda que isso possa produzir em nós, como sujeitos também inseridos em práticas digitais, multimodais, a sensação de que estamos sendo redundantes e apresentando repetitivamente o que a escola, supostamente, experimentaria cotidianamente.

Salientamos que o incidente de Charlottesville nos interessa tanto por seu teor - as violências decorrentes da desigualdade racial, aparentemente desvinculadas do tema apresentado, mas tomadas como mote mais que necessário - quanto pela dinâmica que o discurso em defesa da liberdade estabelece. Sobre o teor, cumpre observar que a questão racial é emblemática de outras violências perpetradas em diversos domínios da vida social, os quais compõem o universo de recortes feitos pelas abordagens críticas de letramento(s) (Cf., por exemplo, FERREIRA, 2006, 2008, 2011, 2014, sobre Letramento Racial Crítico; LUKE, 2009; MOITA LOPES, 2002; SILVA SANTOS, 2011; SANTOS, 2013). Em relação à dinâmica que, ironicamente, coloca uma organização historicamente ligada à luta por direitos (a UALC) em defesa de supremacistas brancos dizerem o que querem, sem que o discurso antirracista tenha igual acesso à esfera pública, podemos afirmar que se repete muitas vezes nos processos sociais, é claro, com outros contornos e feições. Por exemplo, é porque partem de uma racionalidade liberal inscrita em um modernismo emancipatório (PENNYCOOK, 2001), segundo a qual o indivíduo gozaria da capacidade de se responsabilizar por seu próprio destino, que muitos sujeitos, frequentemente em situação de vulnerabilidade social, posicionamse contra políticas de Estado voltadas para o alívio do sofrimento de grupos em desvantagem socioeconômica, como fazem as classes média e média alta brasileiras, por exemplo, em relação ao projeto Bolsa Família, pejorativamente apelidado "bolsaesmola". Políticas às quais se atribui o adjetivo 'populista', um termo controverso na literatura política, que indicaria, no caso da crítica ao Bolsa Família, um alegado assistencialismo e apelo ao carisma junto às massas. Novamente, trata-se de uma atribuição baseada na falácia da igualdade, quando, na verdade, uma gestão socialmente referenciada precisaria reconhecer a inevitabilidade de se repararem os danos historicamente sofridos pelos grupos sociais, possibilitando que usufruam da (re)distribuição direta de renda, como é o caso do programa mencionado como exemplo.

Nesse sentido, tentando juntar as pontas dessa analogia com o letramento, é arriscado confiarmos na suposta condição apriorística de liberdade de ação e pensamento dos sujeitos no ambiente educacional, frente às práticas e eventos de letramento, pois isso os colocaria em uma simetria social quimérica e, portanto, violenta, uma vez que não há igualdade de condições para todas e todos como 
ponto de partida. Em outras palavras, é necessário que primeiramente se reconheça a dinâmica supramencionada como parte de uma base não equânime, não subsumindo a ela a experiência educacional, mas promovendo, afirmativamente, experiências de letramento em que os sujeitos se engajem na práxis da construção dos instrumentos para a transformação de sua própria condição.

\section{EDUCAÇÃO CRÍTICA E LIBERDADE COMO PRÁXIS}

As perspectivas críticas sobre a educação nos levam constantemente a revisitar o conceito de liberdade através de lentes, como as que, por exemplo, Pennycook (2001) apresenta, quais sejam, as disparidades (acesso desigual aos bens materiais e culturais), o domínio (efeitos contingentes e contextuais do poder), o desejo (a ligação entre ideologia, agência e identidade) e a diferença (compromisso com a diversidade e transformação social). Uma vez consideradas essas propriedades de qualquer abordagem que se queira crítica, a noção liberal de liberdade (aquela que emerge na fala de Trump, no argumento da UALC, na crítica aos programas de distribuição direta de renda) relativiza-se, conjurando a composição de ecologias em que nossas vivências em relação à assimetria de poder, disparidades, desejo e diferença fertilizam-se mutuamente na práxis que se instaura.

No prefácio a uma das obras seminais do letramento crítico brasileiro, Educação como prática da liberdade, de Paulo Freire (1967), Pierre Furter lembra-nos que o autor

se permite de [sic] falar em liberdade, em democracia ou em justiça porque crê nestas palavras e no seu poder libertador, na medida que encarnam a sua fé inteira, com todas as suas consequências, até as mais concretas [e que] só então, a palavra, em vez de ser o veículo das ideologias alienantes e/ou de uma cultura ociosa, tornar-se-á geradora, isto é, o instrumento de uma transformação global do homem e da sociedade. (FURTER, 1967, p. x)

Furter sublinha o poder da palavra, que, no caráter "oral" e fluido de Freire, deixa de ser oca e não mais se esconde no verbalismo, "formalismo, beletrismo, o cinismo da descrença tão característicos das elites no poder" (p. x). Essas afirmações de Furter nos lembram da consistência resultante da necessária indissociabilidade entre a experiência vivida, o discurso e sua incidência sobre nosso corpo, ou seja, "com todas as suas consequências, até as mais concretas". O leitorado de Freire é instado, segundo Furter (1967, p.x), a "uma crítica radical da aparente democracia brasileira", que prevê

que ninguém numa democracia seja excluído ou posto à margem da vida nacional (...). Uma educação como prática da liberdade só poderá se realizar plenamente numa sociedade onde existem as condições econômicas, sociais e políticas de uma existência em liberdade. 
Por consequência e porque não pode haver renovação pedagógica sem uma renovação da sociedade global, as exigências pedagógicas de Paulo Freire o levaram também a assumir uma posição política.

Quando, pois, fomos substantivamente democráticos? Quando fomos livres, se a linha divisória entre os abastados e os condenados jamais deixou de existir? Essas condições econômicas, sociais e políticas constitutivas condicionantes do conceito de liberdade que acolhemos podem acabar sendo escamoteadas nas práticas de letramento, se nossa referência se mantiver no campo tecnocrático, instrumental - procedimental relacionado aos eventos de letramento. Trata-se não de ignorar essa dimensão também constitutiva das práticas sociais de leitura e escrita contemporâneas, mas de não prescindir das desigualdades e assimetrias entre os contextos escolares, normalizando a privação. Pressupor que os diversos letramentos estão à nossa disposição impede-nos de levar em conta a historicidade de um sistema que não tem, necessariamente, sido terreno de agenciamentos de transformação social através das políticas identitárias que se estabelecem na dinâmica fluida da multimodalidade do mundo tecnologizado.

Em sua discussão sobre a influência da distribuição do capital cultural sobre as práticas de letramento digital dentro e fora da escola, Windle (2014, p. 199, tradução nossa ${ }^{8}$ ) analisa "as dinâmicas sociais que restringem o poder transformador, especificamente em relação às experiências de jovens migrantes e das classes populares, com a instituição escolar". Ele constata que as práticas escolares de letramento digital carecem de uma crítica que incorpore as questões do capital cultural e da classe social, o que tem como consequência, argumenta, a reprodução cultural e social do prestígio das elites. O campo de ação se mantém, portanto, aberto, convocando uma práxis educacional que catalise transformações sociais. Windle (2014, p.202, 203, tradução nossa ${ }^{9}$ ) provoca-nos à reflexão:

8. "(..) the social dynamics which constrain such transformative power, particularly in relation to the experiences of what migrant and working-class youth with the institution of formal schooling." (WINDLE, 2014, p.199)

9. "The key question addressed here is what recognition subaltern cosmopolitan practices are afforded? What forms of capital do they reflect and contribute to? And in which field are they intelligible as stakes? The ethnographic analysis of new literacies studies seeks to move beyond a competency-based approach, but does not fully identify how digital practices map into social relations of inclusion and exclusion - except to note that they are not mobilised at present at school. The policy prescription is therefore sometimes naive in ignoring the investments in schooling of various social interests and various regimes of value that exercise gate-keeping roles." (WINDLE, 2014, p. 202, 203) 
A questão chave que abordamos aqui é qual o reconhecimento que as práticas cosmopolitistas subalternas recebem? Quais formas de capital elas refletem e com quais contribuem? Em quais áreas elas são perceptíveis como parte constitutiva? As análises etnográficas dos estudos de novos letramentos propõem-se a ir além da abordagem baseada em competências, mas não identificam plenamente quais práticas digitais integram-se às relações sociais de inclusão e exclusão - excetuando-se o fato de perceberem que não estão sendo mobilizadas na escola, no momento presente. Portanto, a adoção de políticas é às vezes ingênua por ignorar no sistema escolar os vários interesses sociais e os vários regimes de valor que exercem funções de controle.

Nossa argumentação apresentada inicialmente é a de que não podemos pressupor a existência de condições para a apropriação das práticas sociais de leitura e escrita multimodais. De todo modo, como corolário da argumentação de Windle, temos que, mesmo quando há condições para a incorporação de práticas digitais na pedagogia de língua, continuamos, não raro, subtraindo de nossa ação pedagógica sua potência política, no mesmo sentido indicado por Pierre Furter sobre a pedagogia de Paulo Freire. Como estão as escolas hoje? Quem nelas atua? Como interagem os sujeitos? Quais forças incidem nesse espaço? Quais são as reais possibilidades de nesse espaço se produzir "em cada indivíduo singular a humanidade que é produzida histórica e coletivamente pelo conjunto dos homens", para usar uma definição histórico-crítica de educação? (SAVIANI, 1995, P.17).

O que gostaríamos de indicar é que a possibilidade de escolha de recursos semióticos e de textos cada vez mais multimodais não é, necessariamente, a realidade da maioria das escolas do sistema educacional brasileiro e tende a ser cada vez menos provável diante do que temos vivido, sobretudo, mas não somente, depois do golpe jurídico-midiático de 2016, que tornou ainda mais distante do que era a construção efetiva de um país socialmente mais justo. Destaque-se, apenas a título de ilustração dessa improvável garantia de agência dos sujeitos no cotidiano escolar atual, a recente aprovação da Reforma do Ensino Médio pelo Senado brasileiro, feita aligeiradamente através de uma Medida Provisória (a MP 746), sem garantir a escuta e a deliberação das diversas instâncias que compõem o sistema representativo popular (conselhos, fóruns) e sendo até mesmo considerada inconstitucional pelo próprio Ministério Público. A reforma do Ensino Médio sequestra, por exemplo, o direito conquistado de figurarem no currículo conteúdos como filosofia e sociologia, para mencionar apenas um dos diversos desdobramentos de uma reconfiguração que, para ser realmente reflexiva das demandas sociais, deveria ter sido objeto de amplo debate na sociedade como um todo, assim como o foi a construção da Lei de Diretrizes e Bases da Educação (1996) que a referida reforma altera substancialmente. Portanto, uma pedagogia que se volte para a liberdade como práxis, inseparável de compreensão do "crítico" na 
ideia de letramento, não deverá se furtar ao enfrentamento da realidade cada vez mais desigual, na qual as assimetrias são legitimadas institucionalmente, ou seja, uma pedagogia que reconheça a instituição educacional como reguladora da mobilidade dos sujeitos e, assim, assuma um modo menor de operação ${ }^{10}$, explorando a potência de agenciamentos apesar das instituições que temos. A sociologia da educação de Bourdieu assim nos subsidia:

A mobilidade controlada de uma categoria limitada de indivíduos cuidadosamente selecionados
e modificados por e para a ascensão individual não é incompatível com a permanência das
estruturas, sendo (...) inclusive capaz de contribuir para a estabilidade social da única forma
concebível em sociedades baseadas em ideais democráticos e assim ajudar a perpetuar a
estrutura de relações de classe. (BOURDIEU, 1996, p. 64, tradução nossa, a partir do inglês ${ }^{11}$ )

Podemos mesmo dizer que há uma relação dialética entre a escola que temos e o mundo multimodal das novas tecnologias digitais, das mídias móveis, que alteraram significativamente nossas práticas linguageiras ao ponto de ser possível considerar dada essa integração? De quais escolas estamos falando? De quais escolas precisamos falar? Como não há, necessariamente, essa integração crítica e criativa entre escola e multimodalidade, se pensarmos com Bourdieu que "A apropriação dos bens simbólicos pressupõe os instrumentos para apropriação" (1996, p. 65, tradução nossa ${ }^{12}$ ), poderemos concluir que nossa sensação de que se goza da possibilidade de escolha de recursos semióticos é, na verdade, o efeito material do discurso de despolitização da experiência escolar. Isso pode ser exemplificado com a própria organização física das escolas, que separam os estudantes por idade, tempo de escolarização; das salas de aula, com a disposição das carteiras e/ou a dinâmica interacional que (re)produz o protagonismo da professora ou do professor e sua posição prestigiada; dos horários, estabelecidos de cima para baixo, sem que os estudantes participem dos processos decisórios; dos currículos propostos, que compartimentalizam o conhecimento, para mencionar apenas algumas características da instituição escolar que circunscrevem a ação dos indivíduos à reprodução das relações de produção capitalista: hierarquizada, utilitarista, voltada aos "saberes práticos", tecnicista, orientada para o produto, baseada em desempenho, focada

10. Cf. Autor (2013) para o conceito de pedagogia menor.

11. The controlled mobility of a limited category of individuals, carefully selected and modified by and for individual ascent, is not incompatible with the permanence of structures, and (...) it is even capable of contributing to social stability in the only way conceivable in societies based upon democratic ideals and thereby may help to perpetuate the structure of class relations. (BOURDIEU, 1996, p.64)

12. The appropriation of symbolic goods presupposes the possession of the instruments of appropriation (BOURDIEU, 1996, p.65). 
em resultados, asséptica em relação ao dissenso constitutivo de toda organização democrática, homogeneizante, despolitizada e mantenedora da divisão social do trabalho.

Dito de outro modo, não se reproduzem, necessariamente, na educação institucionalizada, as experiências que os sujeitos podem explorar/exploram através dos eventos multimodais de letramentos de base (grassroots). A fim de ilustrar essas experiências, as reconfigurações da relação do indivíduo com as práticas sociais de leitura e escrita poderão incluir exemplos, tais como (1) a posição de protagonismo - ao criar um evento ou um grupo de discussão nas redes sociais e pautar assuntos de seu interesse $;$ (2) a sensação de liberdade para se expressar verbal, visual, gestual ou fisicamentepor menos substantiva que possa ser essa "liberdade" - nas comunidades de prática em que se insere; (3) a elasticidade da língua enquanto fenômeno e lugar de interação, quando usada nos aplicativos de envio de texto; (4) o contato com a diversidade (étnicoracial, sexual, geracional, de gênero, socioeconômica, política, ideológica, cultural, etc.) que as mídias digitais propiciam; (5) o trânsito entre os registros oral e escrito e entre gêneros discursivos, suportes, modos de circulação, contato com interlocutores não previstos quando, por exemplo, carrega vídeos em plataformas diversas, entre outras experiências; (6) a familiarização com temas de relevância nacional e internacional, ainda que não necessariamente de modo aprofundado.

Em última análise, contudo, trata-se menos de nos preocuparmos se a escola incorporou a digitalidade e consequente multimodalidade e reconfiguração epistemológica delas resultantes do que se, tendo incorporado ou não, abriga agentes dispostas a localizar suas fraturas, suas brechas, privilegiando uma pedagogia em que o 'crítico' inscreva uma agenda necessariamente revolucionária pela qual a escola constitua a extensão do campo de luta, ainda que a educação não seja a "determinante principal das transformações sociais", como nos lembra Saviani (1999, p.75). Nesse sentido, é preciso desenvolver práticas de letramento no ensino de línguas que partam de uma base socialmente referenciada e incorporem ou lancem mão das epistemologias e recursos materiais que a digitalidade produziu. $\mathrm{O}$ contrário, isto é, a multimodalidade subtraída de sua potência sociológica também é possível - e cada vez mais frequente - embora comprometa a pedagogia de língua que se diz libertária e crítica.

\section{DE LETRAMENTO COMO PROJETO DE EXCEÇÃO}

Poucos termos no campo da educação se deslexicalizaram ou saturaram tanto quanto letramento - embora o termo crítico seja, provavelmente, o campeão 
inconteste. Se, à primeira vista, alguém poderia ter a sensação de que dizer letramento tornou-se vago, requerendo uma especificação, a flexão de número (pluralização), os acréscimos lexicais (estudos de, crítico, novos), o uso de parênteses com prefixos (multi) ou de maiúsculas sinalizaram, a cada alteração, uma marcação epistemologicamente significativa e historicamente traçável. Assim, nosso uso frequente da expressão práticas de letramento ao longo desta conversa recobre visadas do texto, da língua, do sujeito, que poderão variar sutilmente de uso para uso. Apresentamos estas considerações para endereçar a questão apresentada no início deste trabalho, a respeito da conceituação de letramento como tarefa atualmente urgente, em vista da dessemantização que, argumentamos, sofreu neste estágio avançado do capitalismo.

Duboc (2012, p. 73) percorre a historiografia das nomenclaturas que atravessam o tema e que aos termos imprimiram nuances e contornos díspares, apontando, contudo, o lastro comum a todas as "linhas de pesquisa", o qual, em sua leitura, é "a ruptura com o conceito liberal-humanista de letramento, fundado em preceitos biológicos." (p. 74).

Como sintetiza Duboc (2012, p. 74), os novos estudos de letramento (do inglês New Literacy Studies), na década de 80, marcaram a distinção entre (1) a apropriação da tecnologia de leitura e escrita situada na dimensão cognitiva do letramento, ligada ao código e (2) a apropriação de práticas sociais de leitura e escrita, notadamente influenciados pela pedagogia de base marxista de Paulo Freire, pelos Estudos Culturais, que se consolidavam então como campo prolífico, entre outras áreas de estudo. Merece nota o papel preponderante da transdisciplinaridade na consolidação de um novo paradigma para as práticas de letramento. As alterações, desde então, deram enfoque a mudanças epistemológicas, com destaque para a digitalidade, nos anos 90 (novos letramentos); às questões ligadas à diversidade contempladas de algum modo pelo multiculturalismo, multilinguismo e multimodalidade em meados dos anos 1990 (multiletramentos) e, finalmente, a uma "atitude filosófica" (DUBOC, 2012, p.82) que atravessaria, segundo a autora, as diversas acepções de letramento, privilegiando questões ligadas à heterogeneidade, ao dissenso e agência - conceito que acolhe em sua pesquisa sobre a formação de professores. Segundo Duboc, o letramento crítico encerra, a um só tempo, a consolidação de uma "linha de pesquisa independente" e de uma "postura filosófica" (p. 87), asserções que trazem implicações diretas para o distanciamento que a pesquisadora assume em relação à pedagogia crítica de Freire, sobretudo no tocante ao abandono que ela julga necessário da "agenda revolucionária" (p. 84), ponto ao qual voltaremos logo adiante. 
Feito este breve inventário das trajetórias ligadas ao campo dos letramentos e, retomando a questão por nós colocada sobre a conceituação desse campo, entendemos que as concepções de língua decerto incidirão sobre o modo como se promovem práticas de leitura e escrita. Com Monte Mor (2011), entendemos que a multimodalidade gera o encadeamento de eventos que produziram e produzem mudanças conceituais, que, por sua vez, produziram e produzem mudanças epistemológicas que também se apresentam, de alguma forma, ainda que heterogeneamente, nos cotidianos escolares em que o currículo é prescrito e vivido. Contudo, não foi o caráter centrífugo da língua em si que provocou as alterações sistemáticas nas práticas de letramento, como talvez se depreenda da história dos termos, mas o uso e ensino da língua, bem como a teorização sobre estes últimos, os quais se reconfiguraram na medida em que o trânsito interdisciplinar se intensificou em decorrência de eventos históricos diversos e em que as tecnologias de informação e comunicação transformaram nossas práticas e nossa relação com os variados sistemas de representação. Note-se, apenas, que a pluralização de 'letramento', bem como as demais alterações morfológicas, lexicais, etc., ainda que também tenham sido deflagradas por eventos, processos, demandas externas, refletem sobretudo mudanças endógenas no campo educacional em que as práticas de letramento têm sido estudadas, e que incluem a língua, mas não são dela causa direta ou exclusiva. Não se trata, portanto, de ser necessária/desnecessária esta ou aquela forma/expressão ligada a letramento, trata-se mais de qual enfoque ou ênfase se deseja dar.

De todo modo, ajustando a lente que escolhemos neste final de prosa, entendemos que imprimir a "letramento crítico" no singular uma orientação singular, no sentido crítico mais comprometido com a práxis problematizadora (Pennycook, 2001), acolhido por Duboc e muitas outras pesquisadoras e pesquisadores brasileiras(os), requererá de nós, entre outras coisas, um exercício de autorreflexividade, indicado por Pennycook nesse que é um dos textos seminais da Linguística Aplicada Crítica e por ele reiterado diversas vezes, inclusive em sua instigante provocação na conferência de abertura do I International Congress of Critical Applied Linguistics (ICCAL), na UnB, em 2015: "o que acontece quando todo mundo se torna crítico?" (what bappens when everyone becomes critical?). Na insistência de fazer esse exercício, estendemos a conversa mais um pouco, convidandoas(os) a um questionamento que nos fazemos sempre e que gostaríamos de dividir com a comunidade de professoras(es), pesquisadoras(es) desse campo: nossa produção de conhecimento sobre a educação escolar tem se engajado efetivamente com a coletividade sócio-histórica? Malgrado as diversas (e louváveis) formas de 
colaboração entre universidade e escola, nas pesquisas e em ações de diversos atores do contexto escolar (incluindo alunos, professores, gestores de diversos níveis e, às vezes, até a comunidade local onde está situada a escola), documentadas em pesquisas da área, é inegável a histórica divisão hierárquica universidade/escola. E essa divisão demanda que continuemos consolidando práticas de pesquisa com a educação escolar e não apenas sobre ela, ainda que estejamos sujeitos a aflições, escorregões e deslizes de todo tipo; que continuemos vivenciando com a escola e, fisicamente, na escola algumas contradições que expressamos ao afirmar a relação dialética imprescindível entre nossa produção de conhecimento e a "proliferação de aproximadas compreensões, vivências, traduções do cotidiano escolar comprometidas com reais intervenções na violenta realidade social e econômica brasileira." (ZAIDAN \& JUSTINIANO, 2017, p. 316).

Insistimos nesse exercício de autorreflexividade, entendendo ser inerente à crítica a recuperação constante e cíclica da "agenda revolucionária", entendida como um engajamento com a ruptura em relação aos processos e mecanismos que produzem a desigualdade. Ou seja, embora me afaste de Duboc (2012) para afirmar, contrariamente à sua proposta, a necessidade, sim, de uma prática revolucionária, como ela também rejeito investidas supostamente críticas que se proponham a "empoderar" o outro, num fetichismo firmado na fé no indivíduo como valor, que se revela inócuo por sublinhar as subjetividades em detrimento da coletividade e, assim, manter-nos presos nas malhas que nos impedem de combater, de modo teoricamente informado e através de ações políticas concretas, a opressão de quem vive do trabalho no modo de produção vigente.

Em todos os níveis da educação pública brasileira, hoje, atenta-se contra sua função emancipatória, a fim de desfigurá-la, de tentar esvaziá-la cada vez mais de sua natureza política, seja através de seu sucateamento material, que está em franca consecução, seja pelo acolhimento de projetos como o Escola sem Partido, atualmente em vigência em diversos municípios brasileiros; a Reforma do Ensino Médio; a composição da Base Nacional Comum Curricular, cujo processo se orientou sobretudo pelos reformadores empresariais da educação brasileira (FREITAS, 2014; SÜSSEKIND, 2014); a suspensão dos Programas de Combate ao Analfabetismo; os cortes no orçamento de programas de educação popular como o Educação de Jovens e Adultos e o Pró Jovem; o fechamento de escolas; a contratação de professoras não licenciadas; a instalação de um projeto de privatização da educação em todos os níveis pelo atual governo de Jair Bolsonaro, inclusive com a proposta de implementar o ensino a distância na Educação Básica. Sem ignorar que resistência e luta salientam-se em situações de repressão, argumentamos pela imprescindibilidade 
da retomada urgente de uma agenda revolucionária, de ruptura não apenas com o que está posto, mas, sobretudo, com as práticas e mecanismos que deram ocasião a que chegássemos onde estamos.

Diante de nossos olhos, enquanto fazemos nossas pesquisas sobre letramento crítico e publicamos nossos artigos e livros - prática indiscutivelmente necessária -, fortalece-se uma concepção cada vez mais asséptica, mercadológica e comoditizada dos processos sociais. Além disso, ganham vulto nas redes sociais e em outros espaços da esfera pública figuras que epitomizam o fascismo, a xenofobia, a eugenia, a misoginia, a homofobia, o ódio de classe, a criminalização da pobreza, o obscurantismo, o culto aos Estados Unidos, o enfraquecimento de nossa soberania nacional, que também se dá pelas práticas linguageiras, afastando-nos cada vez mais da construção histórica coletiva rumo a uma ética da diferença como valor, representada pela Constituição Cidadã de 1988. Nosso papel como intelectuais, estudiosas, pesquisadoras, professoras, agentes ligadas ao sistema público de educação (municipal, estadual e/ou federal) revela-se cada vez mais preponderante em um momento que nos causa a sensação de nunca termos precisado tanto de letramento crítico como agora, assim como a sensação de nunca termos precisado tanto ressignificá-lo rumo à composição de uma práxis revolucionária, diante da conflagração que estamos testemunhando em todas as arenas da vida social, local e globalmente.

A retomada de uma agenda revolucionária no campo dos letramentos resultará no enfrentamento do aplicacionismo que, guardadas as devidas exceções, tende a permear a relação entre a universidade e a escola, a fim de se desfazerem, efetivamente, as remanescentes "representações da universidade como espaço exclusivo da produção de conhecimento e da escola como mero campo de aplicação" (ZAIDAN \& JUSTINIANO, 2017, p. 317). Trata-se de um modo de dinamizar as práticas de letramento não apenas utilizadas em nossa pedagogia de língua, mas incorporadas a nosso modus vivendi com a/na escola, com nossas colegas pesquisadoras, orientandas e outras agentes que atuam nos processos educacionais, abandonando práticas antigas, apenas parcialmente superadas, de "teorização asséptica sobre o espaço escolar, que, ao invés de compreendê-lo, de penetrá-lo, de ser por ele afetada, o produz violentamente." (p. 316).

Cumpre assinalar ainda que esse distanciamento que hierarquiza, mesmo que sutilmente, a relação universidade/escola, coloca-nos na mesma rota racionalista da qual quisemos nos afastar quando negamos a postura liberal humanista na conceituação de letramento. Isso porque a lógica neoliberal nesta quase terceira década do século XXI tem implicado cada vez mais a esterilização das relações e 
a comoditização de todo e qualquer tipo de prática, não sendo circunstancial que o letramento seja tão possivelmente "embalsamável" pelo establishment acadêmico cooptado por essa lógica, assim como as políticas de identidade de gênero, étnico raciais, ligadas à sexualidade, por exemplo, quando decantadas de seu atravessamento socioeconômico, de classe.

Neste final de conversa, gostaria de dizer que, com ou sem o plural, composto ou simples, o letramento singular que precisamos dinamizar hoje, no Brasil, precisará enfrentar, levando às últimas consequências, numa radicalidade revolucionária, o fato de que, na tradição dos oprimidos, "o 'estado de exceção' em que vivemos é na verdade a regra geral", como afirma Benjamin (2005, p. 83), teórico da Escola de Frankfurt com a qual a Linguística Aplicada estabeleceu diálogo quando se quis crítica em sua orientação (PENNYCOOK, 2001, p. 87). Nesse texto propositivo de uma Linguística Aplicada Crítica, o engajamento com a transformação social é indistinto da produção de conhecimento. Ambos compõem um ciclo práxico no qual pensar, refletir e lutar concretamente contra a opressão estão em relação dialética. Assim como estarão a leitura e a escrita - o letramento singular em que insistimos. Na conhecida Tese VIII sobre o conceito de história, Benjamin (2005, p. 83) prossegue, enunciando que

Precisamos construir um conceito de história que corresponda a essa verdade. Nesse momento, perceberemos que nossa tarefa é originar um verdadeiro estado de exceção; com isso, nossa posição ficará mais forte na luta contra o fascismo. Este se beneficia da circunstância de que seus adversários o enfrentam em nome do progresso, considerado como uma norma histórica. $\mathrm{O}$ assombro com o fato de que os episódios que vivemos no século XX "ainda" sejam possíveis, não é um assombro filosófico. Ele não gera nenhum conhecimento, a não ser o conhecimento de que a concepção de história da qual emana semelhante assombro é insustentável.

A admoestação quase centenária de Benjamin resta tão atual quanto o assombro diário que vivemos, seja em relação a crimes como o de Charlottesville, ao assassinato de Marielle Franco, por quase dois anos ainda não respondido pelas autoridades no momento em que escrevo este texto; às lideranças políticas protofascistas que emergem pela própria estrutura democrática - seja em relação à crise do sistema de representação política que tem redundado no desmantelamento e/ou enfraquecimento de estruturas e mecanismos de participação popular em nosso contexto nacional, seja em relação ao nefando anelo por intervenção militar, expresso por parte da população brasileira que banaliza a brutal violência aqui praticada, na forma de tortura, perseguição, expulsão de cidadãos, silenciamento, censura em relação aos assassinatos de mulheres por seus companheiros ou à patologização da homossexualidade. Nesse reinado da violência em que a desigualdade é estruturante do estado de exceção, prevalece sobre todas as 
desigualdades a interdição às riquezas coletivamente produzidas por quem vive do próprio trabalho; riquezas que são por poucos apropriadas violenta e desigualmente. Foi a partir desse plano desigual, de exceção, que Freire propôs uma educação como prática da liberdade que, posteriormente, impulsionou os estudos de letramento. Plano desigual, contemplado honesta e consistentemente por Paulo Freire em sua atuação com as camadas populares de trabalhadoras e trabalhadores no tempo de sua vida, não sendo, em hipótese alguma, circunstancial que sua obra e sua memória estejam sob ataque no Brasil, desde 2016, quando se intensificaram as políticas de terra arrasada, de desmonte gradativo da educação democrática, pública, laica e de retirada de direitos daqueles que vivem do trabalho. Pela tese de Benjamin, a exceção é a norma, competindo sempre ao nosso tempo produzir o real estado de exceção revolucionário, insubordinado à tradição dos oprimidos que consagra a exceção permanente. Um letramento singular se inscreveria nesse campo de exceção da exceção. Revolucionariamente.

\section{REFERÊNCIAS}

BENJAMIN, W. (2005). Sobre o conceito de história. Trad. J. M. Gagnebin e M. L. Müller. In: LOWY, M. (org.) Walter Benjamin - aviso de incêndio: uma leitura das teses "Sobre o conceito de história". Trad. Wanda N. C. Brant; Tradução das teses Jeanne M. Gagnebin e Marcos Lutz Müller. São Paulo: Boitempo, 1940.

BOURDIEU, P. (1996). Cultural Reproduction and Social Reproduction. In: BROWN R. (Org). Education and Cultural Change. Londres: Routledge, pp. 63-92.

BUTLER R. N. Ageism: a foreword (1980). Journal of Social Issues. v. 36, n.2, pp. 8-11.

CAMPBELL. F. K. (2009). Contours of Ableism: The Production of Disability and Abledness. Londres: Palgrave Mac Millan.

DELGADO, R.; STEFANCIC, J. (2001). Critical race theory: An introduction. New York : New York University Press.

DUBOC, A. P.. (2012). Atitude Curricular: letramentos críticos nas brechas da formação de professores de inglês. Tese de doutorado. Programa de Pós-Graduação em Estudos Linguísticos e Literários em Inglês. Universidade de São Paulo, São Paulo. 
FERREIRA, A. J. (2006). Formação de professores de língua inglesa e o preparo para o exercício do letramento crítico em sala de aula em prol das práticas sociais: um olhar acerca de raça/etnia. Línguas \& Letras, v.7, n.12, pp.171-187.

FERREIRA, A. J. (2008). Limites, desafios e possibilidades para aplicação de estratégias anti-racistas e da Lei Federal n ${ }^{\circ}$ 10.639/2003. In: FERREIRA, Aparecida de Jesus (org). PEAB - Projeto de Estudos Afro-Brasileiros: Contexto, Pesquisas e Relatos de Experiências. Cascavel, Pr: Unioeste, pp. 47-60.

FERREIRA, A. J. (2011). Addressing Race/Ethnicity in Brazilian Schools: A Critical Race Theory Perspective. Seattle, WA, USA: CreateSpace.

FERREIRA, A. J. (2014). Teoria Racial Crítica e Letramento Racial Crítico: Narrativas e Contranarrativas de Identidade Racial de Professores de Línguas. Revista ABPN, v. 6. pp. 236-263.

FREIRE, P. (1967). Educação como Prática da Liberdade. Rio de Janeiro: Paz e Terra.

FREITAS, L. C. (2014) Os Reformadores Empresariais da Educação e a Disputa pelo Controle do Processo Pedagógico na Escola. Educação e Sociedade. Campinas, v. 35, n 129, pp. 1085-1114, out.-dez., pp. 1085-114.

FURTER, P. Paulo Freire ou o poder da palavra - Apresentação. In: FREIRE, P. (1967). Educação como Prática da Liberdade. Rio de Janeiro: Paz e Terra.

GOMES, W. S. (2008) Da discussão à visibilidade. In: GOMES, W.; MAIA, R.C.M. (Org.). Comunicação e Democracia: Problemas \& Perspectivas. São Paulo: Paulus, v. 1, pp. 117-162.

HABERMAS, J. (2008). Comunicação política na sociedade mediática: o impacto da teoria normativa na pesquisa empírica. Líbero, São Paulo, ano XI, n. 21, pp. 9-20.

HUME, D. (1888). A Treatise of Human Nature. L.A. Selby-Bigge, ed. Oxford.

LUKE, A. (2009). Race and Language as Capital in School: A Sociological template form language-education reform. In: Kubota. R.; Lin A. (Org.). Race, culture and identities in second language education: exploring critically engaged practice. London: Routledge, pp.286-308

MENEZES DE SOUZA, L. M. T. (2011). Para um redefinição de letramento crítico: conflito e produção de significação. In: Maciel, R.F \& Araújo, V.A.. (Org.). Formação de Professores de Línguas: ampliando perspectivas. Jundiai: Paço Editorial, v. 1, pp. 128-140. 
MOITA LOPES, L. P. (2002). Identidades Fragmentadas: A construção discursiva de raça, gênero e sexualidade em sala de aula. Campinas: SP: Mercado de Letras.

MOORE, G. E. (1903). Principia Etbica. Cambridge: Cambridge University Press.

MONTE MÓR, W. M. (2011) Multimodalidades e comunicação: antigas novas questões no ensino de línguas estrangeiras. Letras \& Letras, [S.1.], v. 26, n. 2, mar. Disponível em: <http://www.seer.ufu.br/index.php/letraseletras/article/view/25637>. Acesso em: 28 jan. 2019.

PENNYCOOK, A. (2001). Critical applied linguistics: a critical introduction. Londres: Routledge.

PRICE, J. M. (2004). Critical Race Theory's Dream Narratives - A Method for an AntiRacist Social Science? In: Studies in Law, Politics, and Society 32. Edited by Austin Sarat and Patricia Ewick. London: Elsevier Publishers. pp. 39-77.

RAJAGOPALAN, K. (1996). On the ideological underpinnings of the theory of speech acts. Revista de Estudos da Linguagem, [S.1.], v. 4, n. 2, p. 105-132. Disponível em: < http:// www.periodicos.letras.ufmg.br/index.php/relin/article/view/1040 >. Acesso em: 28 jan. 2019.

SAVIANI, D. (1999). Escola e Democracia - polêmicas do nosso tempo. Campinas, São Paulo: Autores Associados.

SANTOS, M. S. (2013). A construção de identidades no livro didático de língua estrangeira: uma perspectiva crítica. Dissertação de Mestrado em Linguística Aplicada - Programa de Pós-Graduação em Linguística Aplicada. Universidade de Brasília, Brasília.

SHEAR, M. D. e HABERMAN, M. (2017) Trump Defends Initial Remarks on Charlottesville; Again Blames 'Both Sides". The New York Times. Nova Iorque, 15 de Agosto. Politics. Disponível em: < https://www.nytimes.com/2017/08/15/us/politics/trump-pressconference-charlottesville.html? mcubz $=1>$ Acesso em: 28 jan. 2019.

SILVA SANTOS, (2011). Raça/Etnia, Cultura, Identidade e o Professor na aplicação da Lei n 10639/03 em aulas de língua inglesa: como? Dissertação de Mestrado em Letras. Programa de Pós-Graduação em Estudos de Linguagens. Universidade do Estado da Bahia - UNEB, Salvador. Disponível em: <http://www.ppgel.uneb.br/wp/wp-content/ uploads/2011/09/santos joelma.pdf $>$ Acesso em: 28 jan. 2019 
SOARES, Magda. (2002). Novas práticas de leitura e escrita: letramento na cibercultura. In: Educação e. Sociedade. Campinas, v.23, n.81, p.143-160, Disponível em: < http://www. scielo.br/pdf/es/v23n81/13935.pdf > Acesso em: 28 jan. 2019.

SÜSSEKIND, M. L. (2014) As (Im)Possibilidades de uma Base Comum Nacional. Revista e-Curriculum, São Paulo, v. 12, n. 03 p.1512-1529 out./dez. 2014 Programa de Pósgraduação Educação: Currículo - PUC/SP. pp. 1512-29.

WILLIAMS, P. (1989). Response to Mari Matsuda, Women's Rights. Law Reporter, Vol 11, n.1, 14. Rutgers - The State University, pp. 11-4.

WILLIAMS, P. (1991). The Alchemy of Race and Rights. Harvard University Press: Cambridge, Massachusetts.

WINDLE, J. A. (2014). Digital Literacy, Cosmopolitism and the Subaltern. In: Polifonia, Cuiabá, MT, v. 21, n. 29, pp. 198-214.

ZAIDAN, Junia. C. S. M. (2013) Por um Inglês Menor: a desterritorialização da grande língua. Tese de doutorado. Instituto de Estudos da Linguagem, Universidade Estadual de Campinas. Campinas.

ZAIDAN, Junia C. S. Mattos e JUSTINIANO, Ana Carolina. (2017) Tradução como Vetor para uma Pedagogia Menor no Ensino de Línguas Estrangeiras: cotidianos em uma escola pública. PERcursos Linguísticos. V7, n. 14, pp. 314-31.

Recebido: 28/01/2019

Aceito: 18/09/2019

Publicado: 16/10/2019 